\title{
Diabetic Retinopathy and Pregnancy
}

\author{
J. Cassar, Eva M. Kohner, A. M. Hamilton, H. Gordon ${ }^{1}$, and G. F. Joplin \\ The Endocrine Unit and the Department of Obstetrics and Gynaecology, Royal Postgraduate Medical School, \\ Hammersmith Hospital, London, England
}

\begin{abstract}
Summary. Diabetic retinopathy was found to be present in 12 out of a group of 67 diabetic patients supervised by us during 92 pregnancies, and 3 further pregnant diabetics were referred to us because of retinopathy. The mean duration of diabetes was 13 years (range 3-25 years). Nine patients had minimal retinopathy, 2 had background retinopathy, and the remaining 4 proliferative retinopathy. The cases with minimal retinopathy showed no progression during pregnancy. In 1 patient with background retinopathy there was deterioration. Of the 4 patients with proliferative retinopathy 1 showed regression during the pregnancy, 2 showed advance and were treated with photocoagulation (these 2 patients now have normal vision), while the patient with extensive retinitis proliferans, with retinal detachment in both eyes and previous photocoagulation remained unchanged. The prognosis during pregnancy for patients with diabetic retinopathy is reasonable and has been improved by the advent of photocoagulation.
\end{abstract}

Key words: Diabetes mellitus, pregnancy, diabetic retinopathy, photocoagulation.

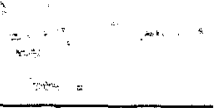

Diabetic retinopathy is of crucial importance in diabetics, and physicians in diabetic clinics are often asked for advice about planning or continuing pregnancy in patients with diabetic retinopathy. In 1950 Beetham [1] suggested that patients presenting with severe proliferative retinopathy should not be permitted to undertake pregnancy. There is little factual information on the effect of pregnancy on diabetic

\footnotetext{
1 Present address: Department of Obstetrics and Gynaecology, Northwick Park Hospital, Watford Road, Harrow, Middlesex
}

retinopathy and still less on the use of photocoagulation. We therefore report our experience with diabetic retinopathy during pregnancy.

\section{Patients and Methods}

Diabetic pregnant women in our clinic have their optic fundi routinely examined early in pregnancy and if diabetic retinopathy is detected frequent checks are carried out throughout the rest of the pregnancy. Diabetic retinopathy was detected in 12 of a group of 67 diabetics during 92 pregnancies, between 1.1.64 and 1.6.76. Three further cases were referred to us specifically for the management of diabetic retinopathy during their pregnancy. These 15 patients had had known diabetes for a mean of 13 years (range 3-25) and all had diabetes diagnosed at an early age (mean 13 years, range 5-23).

The diabetic retinopathy was classified into 3 types: minimal retinopathy with only a few $(<10)$ microaneurysms and haemorrhages in each eye; background retinopathy, which was characterised by a substantial number of microaneurysms, haemorrhages and scattered hard exudates; proliferative retinopathy with new vessels with or without fibrous retinitis proliferans. Reference to grading of severity of lesions in retinal photographs is based upon the Hammersmith Hospital system which uses sets of reference standards [2], expressing the severity of each type of lesion separately from grades 1 to 5 .

\section{Results}

\section{Minimal Diabetic Retinopathy}

Nine patients were included in this group (Table 1). Diabetes was diagnosed at an average age of 15 years (range 6-23) and they had had diabetes for a mean of 10 years (range 3-19). In 4 patients there was no retinopathy detected in examinations $1-3$ (mean 2) years before the pregnancy. The other 5 patients were known to have retinopathy before the pregnancy. There was no significant progression of retinopathy of this type during the pregnancy, as illustrated by case 4 (Fig. 1). 


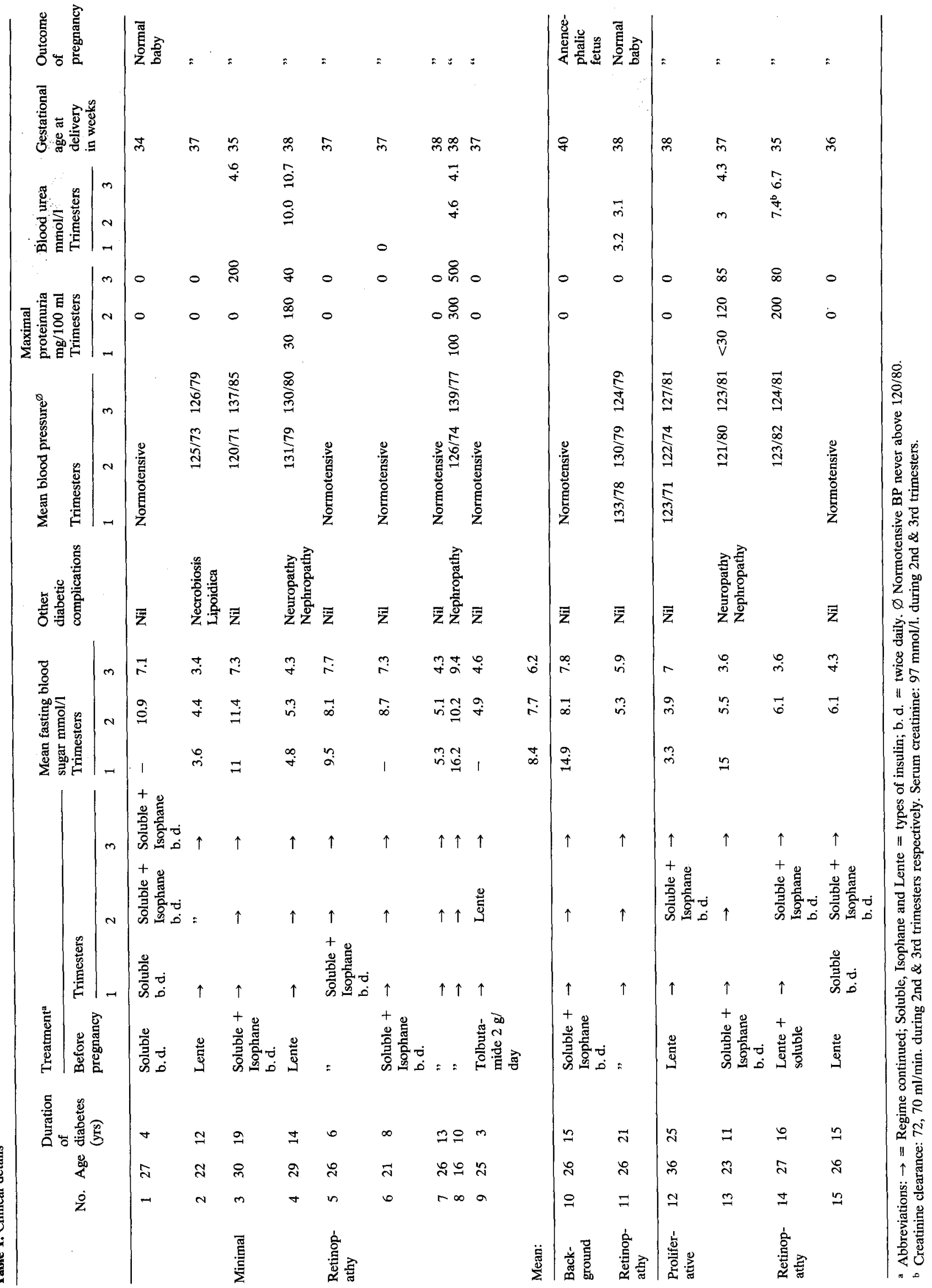



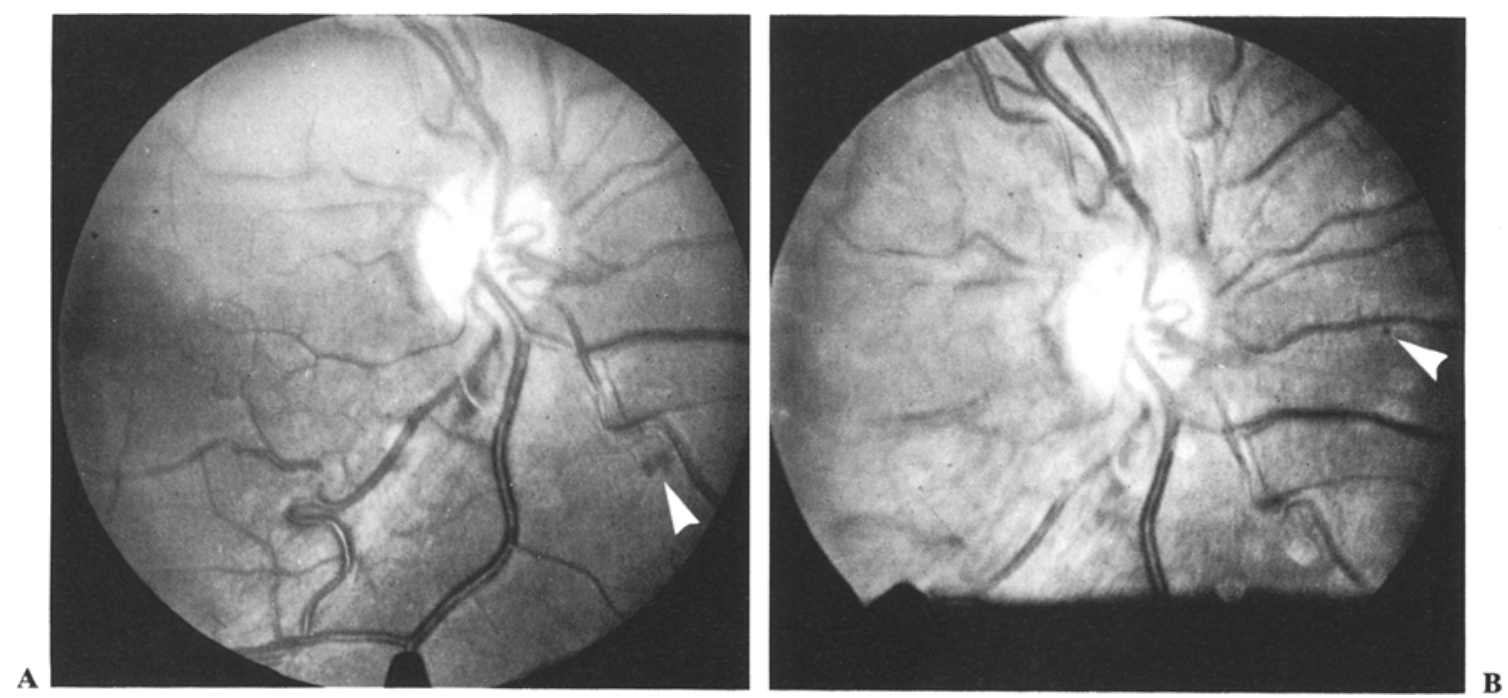

Fig. 1. Minimal diabetic retinopathy before and during pregnancy in patient Nr. 4. A Photograph taken 5 months before the start of the pregnancy, and $\mathbf{B} 4$ weeks before delivery. Haemorrhages are arrowed

\section{Background Retinopathy}

Two patients had this type of retinopathy (Table 1). In patient 10 no retinopathy was observed 4 years before the pregnancy or during the first trimester, but in the second trimester she was noted to have background retinopathy (Fig. $2 \mathrm{~A}$ ) with microaneurysms, hard exudates and some dilated capillaries. The microaneurysms and haemorrhages reached grade 3 in some parts of the retina. There was some improvement of her retinopathy before delivery (Fig. 2B), with further regression postpartum (Fig. 2C and D). Control of her diabetes was poor during the first trimester; however, this improved during the second and third.

Patient 11, when examined 6 years before her pregnancy had no retinopathy, but during the second trimester she was noted to have mild background retinopathy and this improved and was only minimal during the third trimester. This patient also had bilateral lens opacities which were first noted at age 14. Control of diabetes was excellent during the second and third trimester (Table 1).

\section{Proliferative Retinopathy}

Four patients were included in this group (Table 1). Patient No. 12 already had irreversible proliferative diabetic retinopathy. At an eye examination 5 years before the pregnancy she was told she had diabetic retinopathy and 3 years later she had a vitreous haemorrhage and retinal detachment in her right eye. Vision never recovered in this eye. Later on in the same year she had xenon arc photocoagulation in the left eye. The following year, during further photocoagulation treatment to the left eye, she had a "sudden haemorrhage". She was first seen at Hammersmith Hospital when eight weeks pregnant. Visual acuity was down to counting fingers in the right eye and $6 / 12$ in the left eye. In her right eye there was extensive invasion of the vitreous by dense fibrous bands. In the left eye the whole of the vitreous was hazy; there was a large vitreous haemorrhage, an area of retinal detachment and several fibrous bands. Because of the irreversible nature of her retinopathy it was thought that there would be little additional risk to her eyes during the pregnancy. Her insulin was changed from lente once daily to mixed soluble and isophane twice daily and her diabetes was well controlled on this regime. There was no noticeable deterioration of her retinopathy during the pregnancy.

Patient 13 was known to have minimal retinopathy before pregnancy. During the second trimester proliferative retinopathy was observed; she had grade 1 new vessels in a number of areas of her fundi, together with scattered microaneurysms, haemorrhages and hard exudates. There was then regression of the retinopathy during the third trimester with disappearance of the new vessels and 6 months postpartum no retinopathy could be detected. During the second trimester nerve conduction studies showed minimal abnormality, but these reverted to normal during the third trimester. She still maintains normal vision in the right eye 9 years postpartum, but became blind in the left eye 2 years ago. 
A
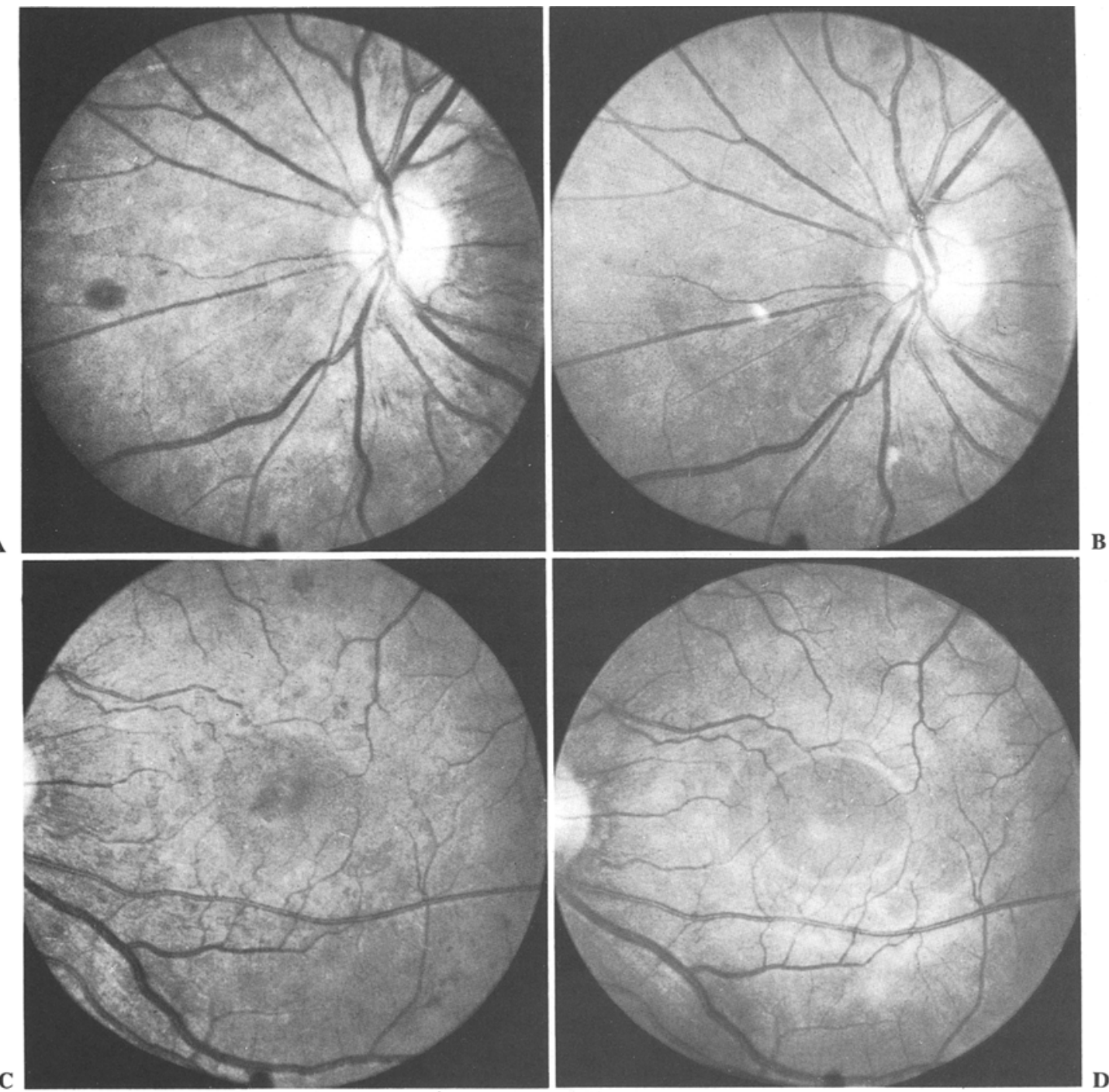

Fig. 2. Background diabetic retinopathy during and after pregnancy in patient No. 10. Photograph of left nasal area during $\mathbf{A}$ second trimester, and $\mathbf{B}$ third trimester (12 days before delivery). Also photographs of left macula during the third trimester $\mathbf{C}$, and following delivery $\mathbf{D}$

Two patients showed relentless deterioration of the retinopathy during the pregnancy and were treated with repeated photocoagulation. These patients have already been reported in detail [3], but a summary of one of the cases is included here.

Patient 15 was known to have no retinopathy 3 months before the pregnancy. When 16 weeks pregnant she presented with blurring of vision and visual acuity was $6 / 18$ on the right and $6 / 12$ on the left. She had microaneurysms, multiple haemorrhages, cotton wool spots, scattered areas of new vessels in both eyes and also new vessels on the optic disc in the right eye (Fig. 3 A). Macular oedema was confirmed by slit lamp examination.

Diabetes was rigorously controlled (Table 1).
There was marked clearing of the macular oedema after starting the patient on diuretics and a salt free diet and this was associated with an improvement in visual acuity to $6 / 9$ in the right and $6 / 6$ in left eye. During the rest of pregnancy xenon arc photocoagulation burns were applied to both eyes and the forward new vessels were treated with the argon laser (Fig. 3B). When 30 weeks pregnant she had two small vitreous haemorrhages from the forward new vessels on the right optic disc. These cleared over the subsequent two weeks. After the 32nd week there was spontaneous improvement in the retinopathy.

After delivery the retinopathy continued to regress and photographs taken 9 months after delivery showed no active retinopathy with no new vessels 


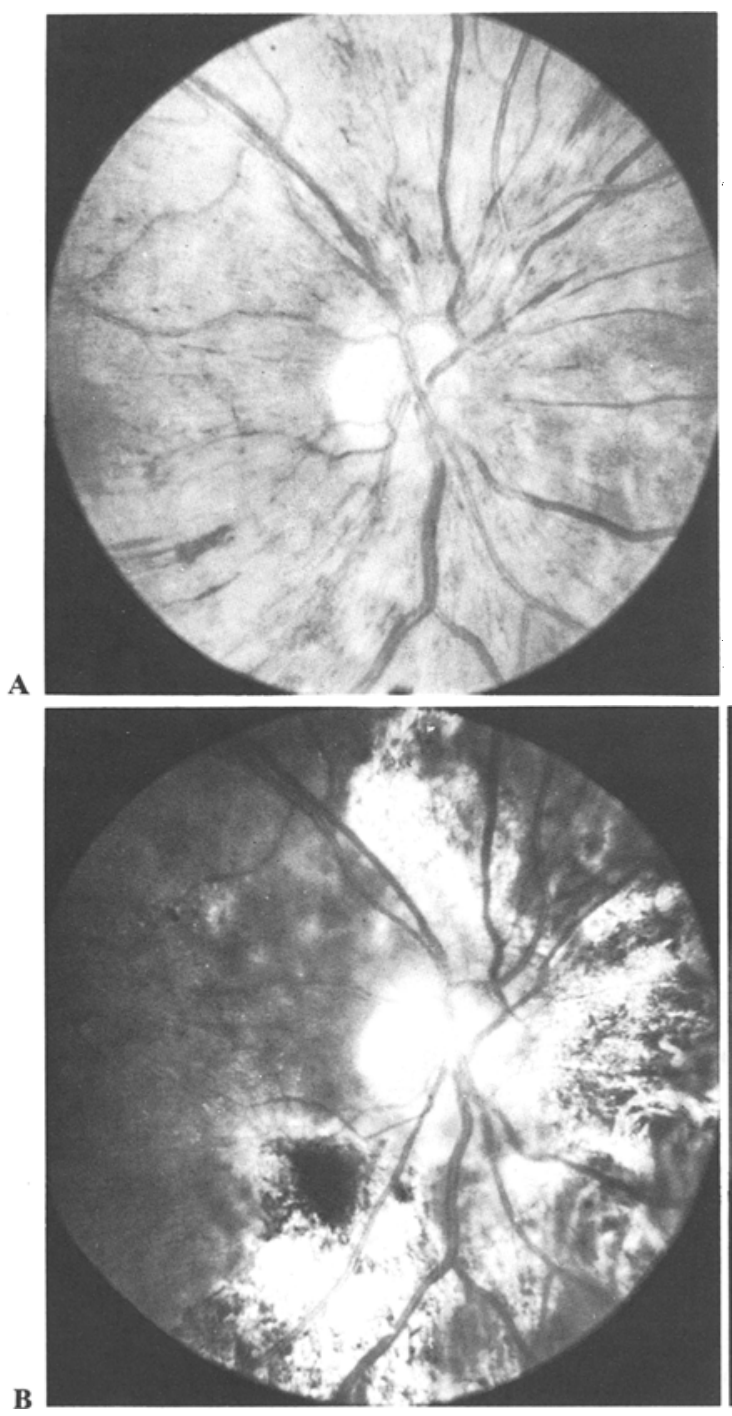

Fig. 3. Proliferative diabetic retinopathy during pregnancy and following delivery in patient No. 15. Photograph of right disc $\mathbf{A}$ at presentation (16 weeks pregnant), $\mathbf{B}$ on the day before delivery following repeated photocoagulation, and $\mathbf{C}$ six months postpartum

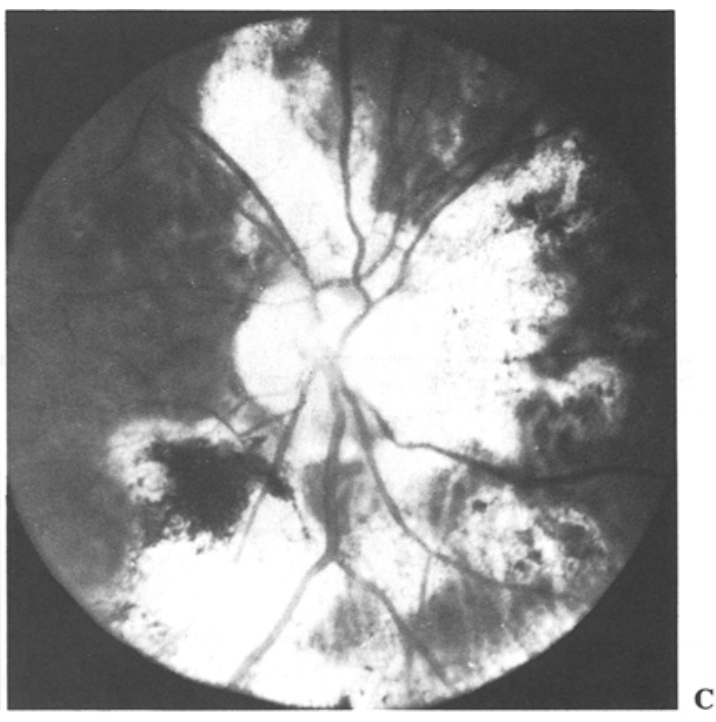

or fresh haemorrhages (Fig. 3C). The visual acuity was $6 / 5$ in both eyes and has remained so 4 years later. She had visual field defects, which she herself had not noticed, corresponding to her photocoagulation scars. In summary, the advance of her retinopathy was halted by photocoagulation.

The other patient previously reported in detail [3] was also managed by repeated photocoagulation during pregnancy. She still has normal vision 6 years postpartum.

\section{Discussion}

Diabetic retinopathy has been observed in approximately $25 \%$ of pregnant diabetics [4]. Excluding the 3 cases who were referred to us specifically because of progression of diabetic retinopathy during preg- nancy, diabetic retinopathy was found to be present in $18 \%$ of our 67 local patients.

A summary of some important literature on diabetic retinopathy during pregnancy is shown in Table 2. All the patients reported had diabetes for over 7 years; however, 3 of our patients with minimal diabetic retinopathy had known diabetes for a shorter time with one patient having had diabetes for only 3 years since diagnosis. All our 4 patients with proliferative retinopathy had diabetes for 11 or more years.

In 3 previous reports, non-proliferative retinopathy progressed during pregnancy in 9 out of 64 $(15 \%)$ cases $[1,6,7]$. In our series, 1 of the 11 cases $(9 \%)$ with non-proliferative retinopathy showed progression during the pregnancy, but with regression of the lesion postpartum, as did one of the above patients. Beetham [1] reported 30 live births in 63 
Table 2. Diabetic retinopathy and pregnancy literature summary

\begin{tabular}{|c|c|c|c|c|c|c|c|c|c|}
\hline \multirow[b]{2}{*}{ Reference } & \multirow{2}{*}{\multicolumn{2}{|c|}{$\begin{array}{l}\text { No. No. of } \\
\text { patients }\end{array}$}} & \multirow[b]{2}{*}{$\begin{array}{l}\text { Duration } \\
\text { of } \\
\text { diabetes } \\
\text { in years }\end{array}$} & \multirow[b]{2}{*}{$\begin{array}{l}\text { Age of } \\
\text { patients }\end{array}$} & $\begin{array}{l}\text { Type of } \\
\text { Retinopathy }\end{array}$ & \multicolumn{2}{|c|}{ Progress of retinopathy } & \multicolumn{2}{|c|}{ Outcome of pregnancy } \\
\hline & & & & & 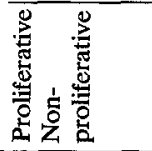 & during pregnancy & postpartum & $\begin{array}{l}\text { No. of } \\
\text { pregnancies }\end{array}$ & Outcome of pregnancies \\
\hline $\begin{array}{l}\text { Lawrence, } \\
1948\end{array}$ & 5 & 2 & $16 \& 19$ & $26 \& 30$ & 2 & $\begin{array}{l}\text { Developed during } \\
\text { pregnancy }\end{array}$ & $\begin{array}{l}\text { Reverted to } \\
\text { normal }\end{array}$ & 2 & "one healthy child" \\
\hline \multirow{2}{*}{$\begin{array}{l}\text { Beetham, } \\
1950\end{array}$} & 1 & 44 & $\begin{array}{l}7-25 \\
\text { average } \\
18\end{array}$ & & 44 & $\begin{array}{l}8 \text { deteriorated } \\
\text { ( } 4 \text { developed } \\
\text { proliferative } \\
\text { retinopathy) }\end{array}$ & & 63 & 30 "living babies" \\
\hline & & 12 & $\begin{array}{l}14-26 \\
\text { average } \\
20\end{array}$ & & 12 & 4 deteriorated & & 18 & one "living baby" \\
\hline $\begin{array}{l}\text { Oakley, } \\
1953\end{array}$ & 6 & 12 & & & 2 & $\begin{array}{l}2 \text { deteriorated } \\
10 \text { unchanged }\end{array}$ & & 14 & $\begin{array}{l}12 \text { "living children" } \\
2 \text { "neonatal deaths" }\end{array}$ \\
\hline $\begin{array}{l}\text { Stephens } \\
\text { et al. } 1956\end{array}$ & 7 & 10 & & & 10 & 1 deteriorated $\rightarrow$ & improvement & 10 & 9 "live babies" \\
\hline $\begin{array}{l}\text { Stephens } \\
\text { et al. } 1963\end{array}$ & 8 & 25 & & & & 2 deteriorated $\rightarrow$ & 1 improved & 25 & $\begin{array}{l}24 \text { "live births" } \\
1 \text { "neonatal death" }\end{array}$ \\
\hline White 1965 & 9 & 87 & & & 87 & 10 deteriorated & & & \\
\hline $\begin{array}{l}\text { Okun et al. } \\
1971\end{array}$ & 10 & 10 & $13-22$ & $22-27$ & 10 & 6 deteriorated $\rightarrow$ & 1 improved & & \\
\hline $\begin{array}{l}\text { Burt \& } \\
\text { Weaver } 1972\end{array}$ & 11 & 2 & $12-15$ & $21-27$ & 2 & $\begin{array}{l}1 \text { deteriorated } \rightarrow \\
\text { improvement in } 1\end{array}$ & $\begin{array}{l}\text { further } \\
\text { deterioration }\end{array}$ & 3 & 3 living children \\
\hline $\begin{array}{l}\text { Martin \& } \\
\text { Taft } 1972\end{array}$ & 12 & 1 & 20 & 26 & 1 & $\begin{array}{l}\text { deteriorated: } \\
\text { hypophysectomy }\end{array}$ & $\begin{array}{l}\text { Improved } \\
\text { in one eye }\end{array}$ & 1 & 1 live child \\
\hline This report & & 15 & $\begin{array}{c}3-25 \\
\text { Mean } 13\end{array}$ & $16-36$ & 4 & $\begin{array}{l}2 \text { deteriorated } \rightarrow \\
1 \text { deteriorated } \rightarrow\end{array}$ & $\begin{array}{l}1 \text { further } \\
\text { deterioration } \\
\text { Improved }\end{array}$ & $\begin{array}{r}4 \\
11\end{array}$ & $\begin{array}{l}4 \text { healthy children } \\
10 \text { healthy children } \\
1 \text { anencephalic fetus }\end{array}$ \\
\hline
\end{tabular}

pregnancies, and Stephens et al. [7] reported 9 live births in 10 pregnancies in diabetic mothers with non-proliferative retinopathy. Ten of our 11 patients had normal births, 1 having had an anencephalic fetus. The outlook for the mother and fetus in this type of patient is therefore reasonable and there is certainly no general contraindication to a pregnancy.

Proliferative retinopathy clearly presents a greater hazard. Twenty of $109(18 \%)$ affected patients showed progression [1,9-10], and two of our 4 patients showed marked progression of retinopathy during pregnancy. However, proliferative retinopathy is likely to progress over 9 months anyway and one of our cases with early proliferative lesions and another with advanced retinitis proliferans showed no appreciable deterioration during the pregnancy: in fact the former patient showed some improvement.

Photocoagulation may arrest diabetic retinopathy [13] and is preferable to pituitary ablation, at least in the first instance, to prevent the more serious complications and yet allow pregnancy to continue. White [14] stated that one of the indications for termination of pregnancy in diabetics was proliferative retinopathy. The use of photocoagulation in our 2 cases with advancing proliferating retinopathy partially arrested the progress of the retinopathy during their pregnancies and both patients still have normal visual acuity. The advent of photocoagulation therefore further improves the prognosis of patients with proliferative retinopathy. All our 4 patients in this group had a live birth, which is in line with the better prognosis for the fetus in these patients in recent years [11], although our numbers are far too small to draw any firm conclusions. In view of the tendency to progression of diabetic retinopathy during pregnancy it seems that diabetics should preferably have their pregnancies early in adult life, before they have significant retinopathy. However, the life span of diabetics with proliferative retinopathy is generally short and such mothers may not live long enough to complete raising their children; one child in five may lose a mother before reaching 10 years of age [14].

We conclude that although diabetic retinopathy may progress during pregnancy and needs careful supervision the prognosis on the whole is good. Pro- 
liferative retinopathy is not an absolute contraindication to pregnancy and the use of photocoagulation further improves the prognosis of these patients.

Acknowledgements. We gratefully acknowledge support for retinal photography made available by the British Diabetic Association.

\section{References}

1. Beetham, W. P.: Diabetic retinopathy in pregnancy. Trans. Am. Ophthalmol. Soc. 48, 205-216 (1950)

2. Oakley, N.W., Hill, D. W., Joplin, G. F., Kohner, E. M., Fraser, T. R.: Diabetic retinopathy. I. The assessment of severity and progress by comparison with a set of standard fundus photographs. Diabetologia 3, 402-405 (1967)

3. Hamilton, A. M., Kohner, E. M., Bowbyes, J. A.: Photocoagulation for diabetic retinopathy in pregnancy. A report of two cases. Trans. Ophthalmol. Soc. U. K. 93, 571-580 (1973)

4. Caird, F. I., Pirie, A., Ramsell, T. G.: The natural history of diabetic retinopathy. In: Diabetes and the Eyes, pp. 72-100. Oxford and Edinburgh: Blackwell Scientific Publications 1969

5. Lawrence, R. D.: Acute retinopathy without hyperpiesis in diabetic pregnancy. Br. J. Ophthalmol. 32, 461-465 (1948)

6. Oakley, W. G.: Prognosis in diabetic pregnancy. Br. Med. J. 1953 II, 1413-1415
7. Stephens, J. W., Holcomb, B., Page, O. C.: Pregnancy and diabetes. Results of management without female sex hormone replacement therapy. J. A. M. A. 161, 224-226 (1956)

8. Stephens, J. W., Page, O. C., Hare, R. L.: Diabetes and pregnancy. A report of experiences in 119 pregnancies over a period of 10 years. Diabetes 12, 213-219 (1963)

9. White, P.: Pregnancy and diabetes. Medical aspects. Med. Clin. North Am. 49, 1015-1024 (1965)

10. Okun, E., Johnston, G. P., Boniuk, I.: Development of diabetic retinopathy. In: Management of Diabetic Retinopathy, pp. 6-48. St. Louis: C. V. Mosby 1971

11. Burt, R. L., Weaver, R. G.: Proliferative diabetic retinopathy in pregnancy. Obstet. Gynecol. 40, 199-201 (1972)

12. Martin, F.I. R., Taft, P.: Hypophysectomy for diabetic retinopathy during pregnancy. Diabetes 21, 972-975 (1972)

13. Multicentre randomised controlled trial. Proliverative diabetic retinopathy: treatment with xenon-arc photocoagulation. $\mathrm{Br}$. Med. J. 1977 I, 739-741

14. White, P.: Pregnancy and diabetes. In: A. Marble, P. White, R. F. Bradley, L. P. Krall (eds.): Joslin's Diabetes Mellitus, pp. 581-598. Philadelphia: Lea \& Febiger 1971

Received: December 28, 1977

and in revised form: March 23, 1978

Dr. J. Cassar

Royal Postgraduate Medical School

Hammersmith Hospital

London W 12 OHS

England 